\title{
INVESTIGATION OF STAGE PHOTOGRAPHY IN JEE LEE'S WORKS AND COMPARINGTHEM WITH THE WORKS OF SANDY SKOGLUND
}

\author{
Pouya Zamanian ${ }^{1,2}$, Mehri Kasiri \\ ${ }^{1}$ University of art, Tehran, Iran \\ ${ }^{2}$ Member of the Faculty of Arts of the University of Isfahan Payam Noor, Isfahan, Iran \\ *Corresponding Author Email: Pouyazamanian@yahoo.com, mehri.kasiri@yahoo.com
}

This is an open access article distributed under the Creative Commons Attribution License, which permits unrestricted use, distribution, and reproduction in any medium, provided the original work is properly cited.

\section{ARTICLE DETAILS}

\section{Article History:}

Received 12 November 2017 Accepted 12 December 2017 Available online 1 January 2018

\section{ABSTRACT}

Staged photography is a kind of art reconstruction, which, unlike intrinsic realistic nature of photography, presents a dramatic and unrealistic identity to the medium. Many artists from the beginning of photography have entered this field. Two of the artists are Sandy Skoglund, an American female artist, and JeeYoung Lee, a Korean artist. Surprisingly, the images of the two artists are very similar to each other. In this research, it is tried to compare the photoscaptured by these two artists and analyze the similarities and differences between the works identified and study the effects they had on one another. The main question of the current research is which one is the leading artist, and which one is the follower, and whether these similarities are indicative of blind imitation or artistic creation? By a qualitative and quantitative comparison of works and photos taken by the two artists and by analyzing the biographical reviews and interviews with the two artists, one can find a common pattern used by both of them and of course, innovations cannot be ignored. Since Skoglundis older than JayYong, and has begun her career earlier, it can be said with certainty that she has inspired Jay Yong. However, artistic abilities and innovative innovations of Jay Yong are admirable. This way of being inspired and creating artwork creates new and exciting works that can be the guide for photographers and fans in this branch of photography.

\section{KEYWORDS}

Staged Photography, Stage, Sandy Skoglund, JeeYoung Lee.

\section{INTRODUCTION}

This article reviews the works of the Korean artist JeeYoung Lee, one of the youngest and innovative artists in the field of photography. The main purpose of the article is to compare the works of the artist with the works of artist Sandy Skoglund, since their photos are very similar to each other. Both artists are women, do stage photography, and neither of them uses computer tools in stage photography .The process of constructing, arrangement, décor, and color combination are some of the issues that make the photos taken by these two artists look very similar to each other. An important issue to consider is the Jay's imitation approach to Skoglund's work. Whether Jay-Ying Li is a mock woman, or her work is a blend of creativity and innovation is an issue that is being addressed in the research .To achieve such a conclusion, it is necessary to compare the works of the two artists and to examine the differences and similarities. In order to better understand the similarities and differences of the works, a definition of staged photography or staged photography is first provided, and then it the lives and works of the two artists are compared with each other.

\subsection{Importance and necessity of the research}

Due to the tendency of Iranian photographers to pioneer art, photography in Iran has found a lot of fans. However, because of the lack of scientific knowledge in this area, the photos captured are, in most cases, a low-level copy of foreign works. Given that photography in Iran follows the Western tendencies, it is better to have conscious and directional imitation if these works are going to be copied. The works of the Korean photographer JeeYoung Lee, though derived from the skoglund's works, are so artistically created that they could find their place in the art world. This research attempts to study the influences of these two artists on each other, so that Iranian photographers will be able to find appropriate ways to create works influenced and inspired by the works of Western artists.

\section{LITERATURE REVIEW}

As to stage photography, there is no comprehensive and comprehensive research study in Iran, and the available information limits to only a translation of important English articles such as "reality or constructed stage" by Roohbakhshan, or "a review of the narrative in a staged photography" by Sharif Zadeh and Khatami. Several translated articles are available in connection with Sandy Skoglund, a staunch photographer.

These include "fox games" by Arash Ahmadi Khalaji [1]. However, in relation to another artist, JeeYong Lee, since she has recently emerged, there has been no research studies not only in Iran but also in the world. There is only one interview which is available in English and has featured several sites that featured her works and briefed on several photos taken by her. In the following article, not only a summary and comprehensive description of the staged photography is provided, but also the methodology of the work of two of the prominent artists of this branch has been analyzed using semantic critique and composition of works in order to pave the way for a better implementation of this method in Iran.

\section{RESEARCH METHODOLOGY}

In this research, the photos taken by two outstanding artists are compared with each other, through descriptive-analytic method, to find the similarities and differences. By studying their biographies and interviews on various websites and books, the influence of them on each other is studied. Then, based on the results, we try to evaluate the artist's works correctly, to evaluate them correctly based on the amount of innovation as well as imitation.

\subsection{Stage photography}

Modernism appreciated the reality and the objectivity in the media of photography, and considered the photographic reality as an inherent characteristic of the media, considering it what called photography's distinctive feature is. This trend, which has been fueled by great art 
historians and planners for many years, has been repeatedly violated by fellow photographers, and took forms different from realism. One of the most different forms of these unrealistic representations was stage photography.

Stage photography, initially born by pseudo-pictorial paintings, either in terms of content or in terms of style was blamed by modernists, including Sarkovsky, and abandoned by the photographic world. This trend continued until the beginning of the postmodern era, but then everything changed at once. The postmodern art that was born in the realm of reality crisis combined the media and lead to the decline of the photographic reality. The valuation of works of art was now based on the scale of distance from realism. This attribute was even applicable in the real-life media, such as photography. Photographers now preferred to construct photos rather than take photos. Pictures were created with staging and storytelling, not by recording actual events .The contemporary stage photographer, considered himself an artist not a photographer or liked to be called so. These artists have tried to create a personalized world through the arrangement and design of the stage and lighting. Artists of this branch, using all the factors used in a cinematic project, photograph special scenes with precise plans. The elements of the stage, such as light, actor, and decor... all serve a static visual image that has a narrative direction [2].

Nowadays, no genre has been as successful as stage photography in making such a close connection between arts. The link between photography, painting, sculpture, and cinema is well established in single frames of photos. In stage photography, sometimes large or very small sculptures play roles in front of the camera, and sometimes live models, with gestures of nineteenth-century Victorian painting boards pose in front of the camera. Some of the scenes have direct references to outstanding works of art history and historical paintings, and in some of the photographs, the atmosphere of surrealist paintings and mysterious spaces filled with ambiguity of horror cinema and criminal stories is dominant. Some people call this photography a photographic drama, because it seeks to create a narrative that is visually enclosed in one or more frames.

All the photos of this style have one point in common: they all have logical narratives; modern narratives of historical and religious themes, cultural and identity allegations, post-colonial issues, racial and class discrimination, and the perplexity of modern and consumer humans in societies full of contradiction between working policies and their consequences and outcomes.

At the time of viewing these works, the audience stands in front of a scene which somehow appears to be a larger version in the form of a fixed frame. The work in front of the audience, due to carefully selected visual elements, on the one hand, and familiarity with visual cinematic language, on the other hand, awakens memories in the minds of the audience that comprise his personal narrative. This narrative is the result of everyday memories and dramatic memory of the audience, and therefore has a completely personal aspect.

The artist gives the audience astatic image and gives him the opportunity to consider this as the beginning, the middle, or the end of his narrative. These images, more than any other experience in the world of photography, are capable of interacting. The audience of these works, on the one hand, identifies each individual component of the image and discovers the inner relations of the image, and, on the other hand, continues making his story until it comes to the point of the story that the image in front of him depicts. Stage photography, due to the presence of dramatic strains, has the potential to stimulate the audience to develop semantic horizons [2].

In contemporary staging, indigenous discourses, environmental issues, women's issues, post-colonial critiques, contemporary policies and disruptions are paid attention to. Stage photographers do not see themselves bound by certain constraints and sometimes use multiple image manipulation techniques and even photomontage. This extension in the way of expression makes it difficult to determine the precise boundaries of stage photography. Andreas Winkel has divided this kind of photography into four types:

First, narrative photos in which live models or mannequins directed by the photographer play roles that portray a historic, mythical, or social life. The works of Tom Hunter belong to this category. He refers to the history of art to describe the problems of today's life, and expresses his concerns in the form of famous paintings of history. The works of Skoglund are also in this category.
The second category is a miniature show similar to small-scale narrative panels featuring dolls and toys, and other small instruments. David Levintal who photographs miniature models belongs to this category.

The third category is related to the layouts and photos of sculptures and objects that are carefully compiled, such as the works of Jen Grever 9 and the final category is staged self-portrait in which the photographer appears in different roles, such as the collection of untitled films by Cindy Sherman 10, in which Sherman appeared with different makeups at different places in the role of various women [3]. In addition, the works of the Korean woman artist JeeYong Lee, who plays and performs on stage with her dramatic staging lie in this category.

\subsection{Korean artist Jee Young Lee}

The work of this artist is a collection of fantasy elements that are arranged in a small, colored room based on the theme, with a special arrangement. The artist herself is also in the middle. At first glance, the picture seems a mixture of a variety of retouching techniques, but in fact all the stage elements and components of the photographer are made by hand and by the artist herself in her small studio .Jee Young Lee was born in South Korea in 1983, grew up in Seoul and is now working there. She is a designer, sculptor, and photographer. She received her undergraduate and postgraduate degree from Shanghai University of Hangik. Her bachelor degree was visual communication design that enabled her to experience different artistic branches. When she eventually decided to become an artist, she sought a medium outlet that could best convey her message to the audience, and eventually chose photography, but before that, she was mostly engaged in filmmaking and worked behind the scenes. At undergraduate level, she was a member of the University Film Club, and all of these experiences were the foundation of her today's work [4].

In her small studio with dimensions of 3.6 by 4.2 by 2.4 meters in South Korea, she spent weeks and even months to create illusory sculptures without any editing and retouching software and created surreal images. The themes Lee chooses for her photos are in many cases, the result of her dreams and aspirations, and sometimes they also represent the traditional stories and legends of the Korean people [5].

In 2007, JeeYoung Lee photographed in a traditional way. while traditional photography provided real-life visuals, a group of artists attempted to present their internal feelings, memories, and dreams in stage photography. Jee Yong, in spite of the inherent limitations of conventional photography, after a while, chose a kind of creativity and theatrical performance. She sometimes spent weeks and even months in her smal workshop on a project and worked with great patience on the details (ibid). Since 2009 to this year, JeeYong has held numerous solo and group exhibitions in Korea and several other countries, including Singapore, the United States, and China

At her first solo exhibition outside Korea, she gained much success at the Opium 13 in France in 2014. In just two days, her works were visited on the Rodeit web site for over 500,000 times and were featured and discussed in various media around the world, including Huffington Post, NBC news, CNN international, and so on. She was called one of the promising artists with a bright future in Korea, receiving prestigious awards, including the Art Surrey Award in 2012.

Jee Yong focuses sometimes on the scenes in her dreams to make her pictures. She then thinks about whether it is possible to build it in the real world. Creating a scene needs a strong visualization and thinking. Her artistic work is a combination of her inner thoughts. She has to figure out what elements can better reconstruct her story and whether the objects made can put her message across. After that, she chooses the color based on the purpose of the subject and the type of subject and ultimately places everything in the final composition so that it looks the most meaningful (2014, hungertv) [4]. She tries to find answers to her questions in life and, through photographic processing, shows her concern about what is happening around her. She does not feel either so young and immature, or so old and wise. She considers herself as a fruit which intends to get ripe. She is an adult who is not fully mature. She reveals her belongings from the world and tries to reflect the impact of the environment on her and her impact on the environment in her works. Many of the works also run away from Korean stories and myths. 


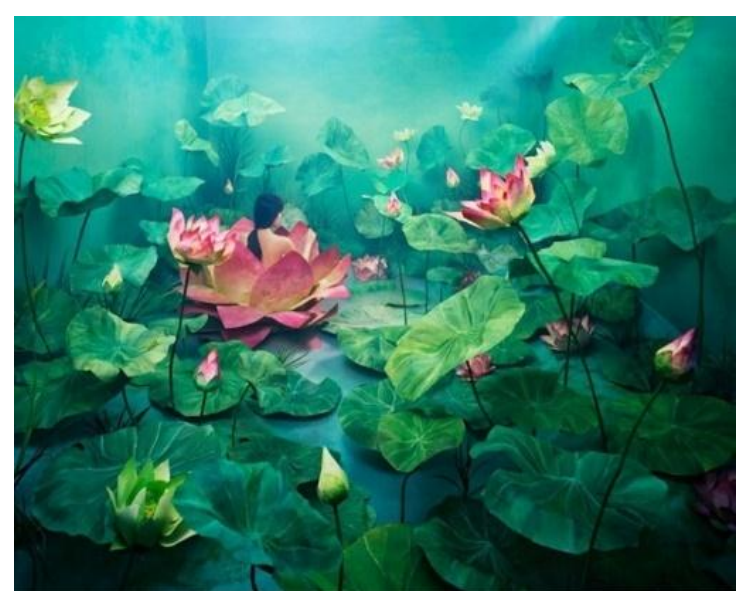

Figure 1: Resurrection (www.opiomgallery.com/en/artistes) [5]

One of her works titled "Resurrection" was inspired by one of Korea's national stories, Shim Cheong, and also the character of Ophelia in Shakespeare's play. Resurrection is the story of a girl who throws herself into the sea and returns to life from inside a lotus flower. For this photo, Jee Yong covered her studio walls with blue green and made flowers and leaves of lotus flower with paper and placed them inside the room. The room was then filled up with fog created by carbon dioxide and ice to create a mysterious atmosphere (Figure1).

Lotus flower grows through the mud and rises to light to blossom. In Asia, this issue also carries other symbolic meanings, such as hope and rebirth. The presence of the artist at the flower center reflects on her personal experiences. Overcoming the negative elements that led her down, the artist was able to reborn with a clean, fresh feeling. This birth helps the photographer to come to maturity, and therefore the name Resurrection is chosen for this work. One of the artists who has unconsciously, or consciously influenced Jee Young is the American photographer Sandy Skoglund. It seems that the obsessive repetition of similar elements, the theatrical composition, and the cinematic narrative that is seen in Jee Young's works is an artistic imitation of Skoglund's works.

\subsection{Sandy Skoglund}

Sandy Skoglund was born in 1946 in Massachusetts. She was fourteen years old when she started working at Disneyland restaurants as waiter. She graduated from Smith College of Art in bachelor's degree and from the University of Iowa, she holds a Master's Degree in Film and Multimedia Arts. A few years later, she continued to study at the same university for a Ph.Ddegree in Minimalism [6]. At age 26, she moved to New York and began working as a novice artist in the art space of the Concepción.

Since she needed to take photographs to record her artistic experiences and works, she self-studied in the field. She began to photograph nature, food, and sculptures. These were the foundation for the formation of the main body of her artistic work, the construction of elements in the form of a statue, designing them in the form desired by the arrangement of things, and using the presence of one or two actors live on the stage and photographing them from the intended angles (ibid). These features are features that are clearly seen in Jee Young's works. A quick glance at the works of these two artists can show many similarities, both in terms of meaning and in appearance. In order to investigate further effects, their works can be compared.

\subsection{Comparative Comparison of the Works of Two Artists}

Skoglund was born in 1946 and is about 37 years older than Jee Young. Many of her works have been created before Jee Yong's birth. Therefore, in a simple estimation, she can be considered a model of Jee Young's in the creation of her staged photographs. To better understand the influence of Skagland on Jee Yong, the similarities between the works can be discussed .Arrangement of stage and staging are the main characteristics of the work of the two artists. Laying unusual elements together and creating surreal situations create a fancy dreaming in the works of the two artists, but what makes these works different from works of other artists and elevates their artistic value is not using any editing software such as Photoshop. All unrealistic aspects of scenes have been photographed by working on real elements. Skoglund believes that doing computer work changes the meaning of a photo. If the viewer knows what he sees has actually existed, the meaning of the work is enhanced [6].
Similarly, Jee Yong does not use computer changes in her works unless she hangs something from the ceiling, then she uses Photoshop to clean the yarn or rope that used for this. This is due, of course, tothe philosophy of her work. The final output of her works is a photograph and it is not necessary to distort the true nature of her work by computer tricks [4]

Another point that makes the artworks of these two artists look alike is the repetition of certain elements similar to each other. Both artists are familiar with the skill of making sculptures and have built many elements for their photos. These elements are repeated at different rhythms in the works of these two artists. These elements, with their abnormal dimensions and with a different function from the real world, are trying to create an extraterrestrial position and have succeeded in achieving it Among the elements made, the sculptures of animals are prominent, and they add to the similarity between the works of the two artists. Most of the repetitive elements in Scoglund's works are animals such as cats, foxes, dogs, squirrels, and fish, each of which is based on symbolic and cultural identity in the artist's staging (such as radioactive cats or fox games)

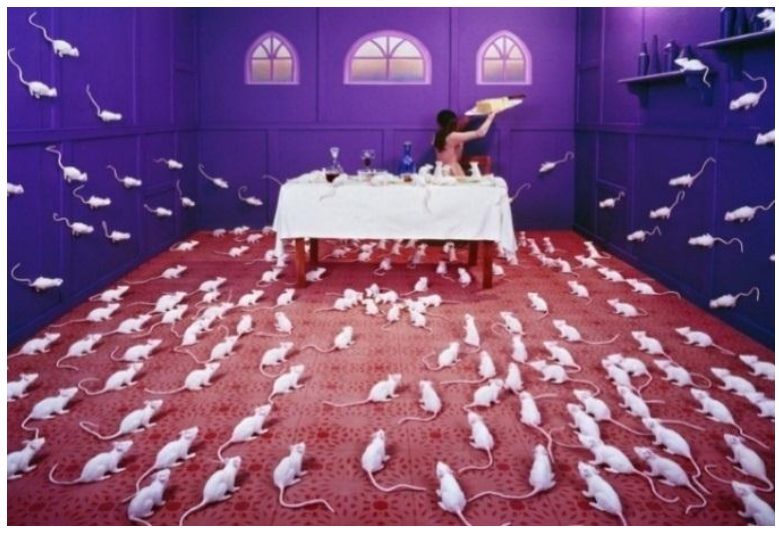

Figure 2: Fox Game

According to Souglund, animals are the bridge of communication between humans and the real and natural world. When we look at an animal, we see a real creature. A creature that does not see the world as we see it [7].

In the fox game, held at the George Pompidou Center in Paris in 1989 on the occasion of the 150th anniversary of the invention of photography, Skoglund has filled a gray dining room with foxes. The room has high ceilings, some windows with shields, a photo frame without a photo, eight tables with curved back seats, and 23 red orange foxes (Figure 2).

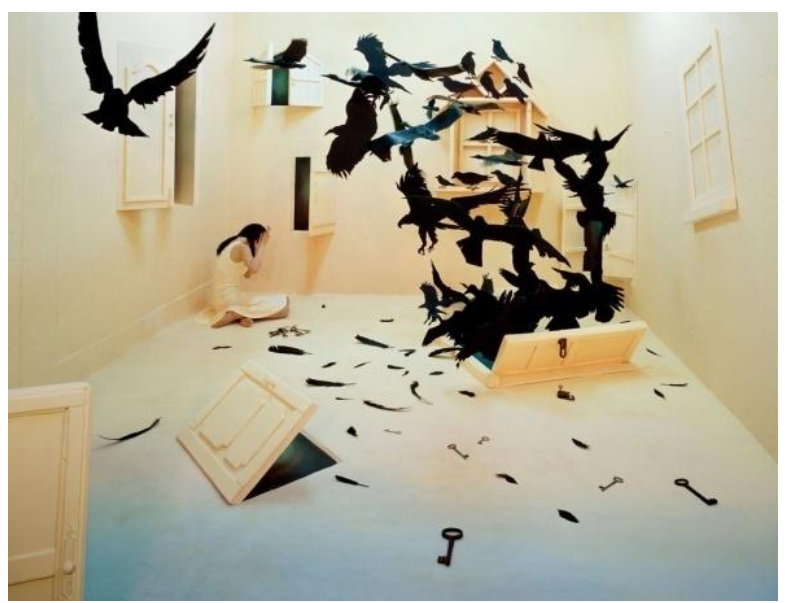

Figure 3: Black Bird (www.opiomgallery.com) [5]

Foxes are very active and uncontrollable, jumping on tables looking for food. The only three people in the photo, a woman and a man and a maid, seem indifferent about their surroundings. The foxes have conquered the room in an unrealistic way and dominate the barbarism in their nature. Although the game of foxes on the tables is fantastic and awesome, it shows brutality. Fear is the essence of the meaning that is transferred to the viewer, both explicitly and implicitly [8]. This fear is similar to the fear that the black birds' withdrawal from the ground transfer to the girl in the corner of the frame created by Jee Yong (Figure 3) 


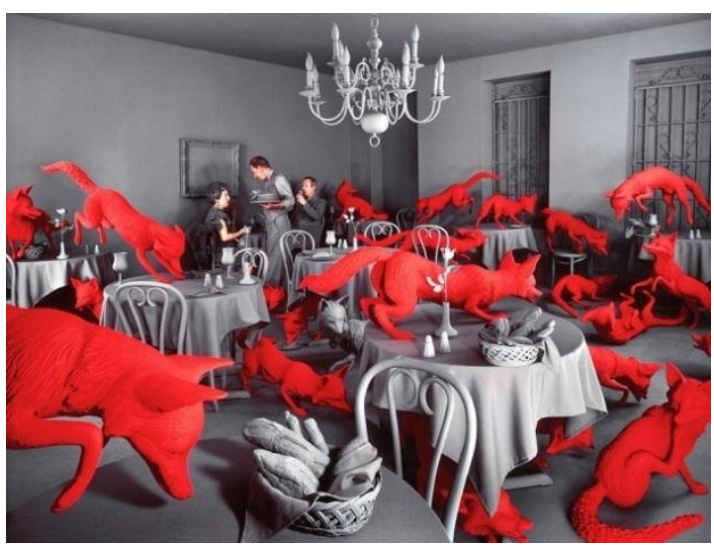

Figure 4: Last Supper (www.hungertv.com/feature/interview-jee-Yonglee) [4]

Animals are repeatedly used in Jee Yong's works, as well. For example, in the last Supper, in the competition for a small amount of food, a large number of mice attack the table, and the main character, the artist herself, is trying to save the cheese plate from their hands (figure 4). In terms of the composition, this photo is inspired by Last Supper by Da Vinci. Another striking resemblance between Jee Yong's and Scotland's works is the inner feeling that each work can transmit. In fact, Skoglund combines visual elements that do not have explicit concept. The dual presence of animals in the works evokes a feeling of anxiety.

In most of Jee Yong's works, the horror and frustration stemming from the artist's inner dislocation can be seen. For example, in "My Chemical Romance", the redundant congestion of yellow and black pipes is a sign that represents the photographer's inner conflict with the surrounding community (Figure 5).

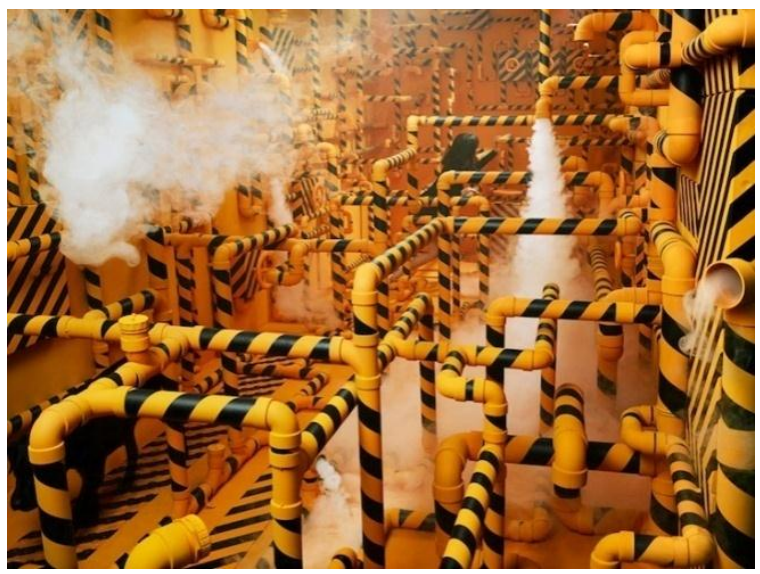

Figure 5: My Chemical Romance (www.opiomgallery.com) [5]

In addition, the steam generated by the mastication device connected to the pipes is a symbol of the moment of the incident and reflects a psychological warfare in the artist's communications. Apart from the sophisticated tubes, a black dog is slowly going out from the bottom left corner of the frame. This dog symbolizes a person who has had a great influence on the artist and her life and has brought her a great deal of pain and now is slowly going out of her life and is also a symbol of the antitheses involved with the artist [9]. But, apart from the similarities between the works of these two female artists, there are also significant differences in the pictures of them. These differences can distinguish Jee Yong's art style from Skoglund's.One of the most significant differences between the works of these two artists is the presence of the Korean artist Jee Yong in most of her photographs. This distinctive quality is not visible in the Skoglund's works. This feature makes the photo a self-portrait image.

However, it is an unusual kind of self-portrait, inspired by the artist's own personal life, combined with legendary Korean legends. These selfportraits have been designed and displayed not for the purpose of displaying herself, but for expressing the wishes and understanding of the artist's inner identity. These self-portraits each relies on a story. In her creative portraits, she is on the path to self-cultivation and self-reflection, which makes it easier for her to accept social repression and constraints. The artist pauses a moment in her inner struggle and takes it away and steps in a way full of hope. Regardless of the photographer's limitations in the field of performance, the main theme of the work, in scenes captured, has a deep root in the artist's inner tendencies. The greatest influential element on Jee Yong's work has been her own personal life. The innermost emotions, the psychological views of the social issues of a Korean citizen, and the daily events affecting her are reflected in her works. Good and bad feelings of human relationships, memories, experiences and changes in the environment are important subjects used in her artistic work.

Another difference between Skoglund and Jee Yong is the semantic nature of the works and the themes used for staging. Scotland's orientation is more towards the social environment. Skoglund tries to express herself in relation to society in her works. Man, in this internal world is very worried about his personal needs while heavily overwhelmed by what is happening in and around his surroundings. Skoglund takes Surrealism into service of social and political interpretations. She is metaphorically and not directly concerned with the work environment, population growth, aging, nuclear war, and so on. For example, in the work of (Babies), apart from the fears caused by the heterogeneous composition of the stage, the semantic load has a political side. In this work, 20 infants are floating in large sizes with shades of pink colors in a black and threatening environment, and a man from the window is looking at them (Figure 6).
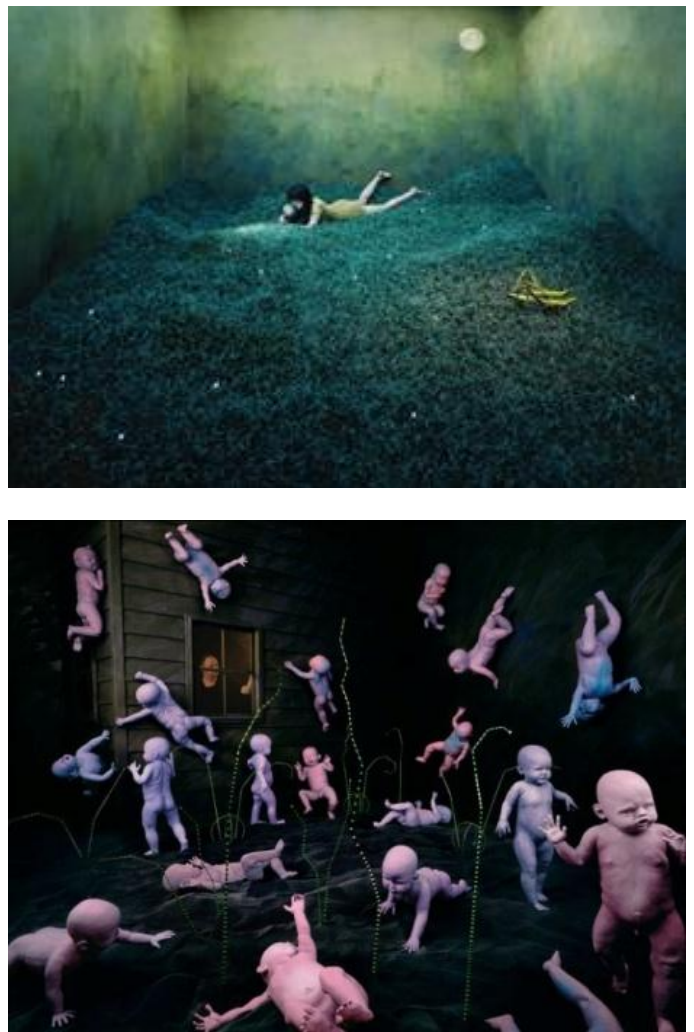

Figure 6: Babies

When it was featured in the LyckCastley Gallery, many viewers saw it as another notion of an atomic massacre. Many also interpreted the blue and pink color on the babies' body as a sign of child abuse, and some also linked it to abortion policy. Opinions that Skoglund did not originally intended, but did not deny them.

Skoglund's works are inspired by the theatrical narratives of the surreal paintings of Salvador Dali, the deceptive sculptures of Rene Magritte and photographs of Mannray. She is inspired by science fiction, horror films, and museums of natural history, shop windows and many other areas for her works [10]. On the contrary, Jee Yong's works are more related to Korean native literature and legends. For instance, the artwork "I'll be back" is based on a Korean legend. In this legend, an angry tiger chases an unlucky child into a well. God sends a rope from the sky to get the child out of the well but when the tiger cries, God sends him a rotten rope, and the tiger will be condemned to a miserable destiny. In this work, a hand is stretched out through a whirlwind, carefully and obsessively crafted by thousands of traditional blue-haired fans, ready to get a hanging rope, hoping to save himself from the difficult situation he is in (Figure7). 


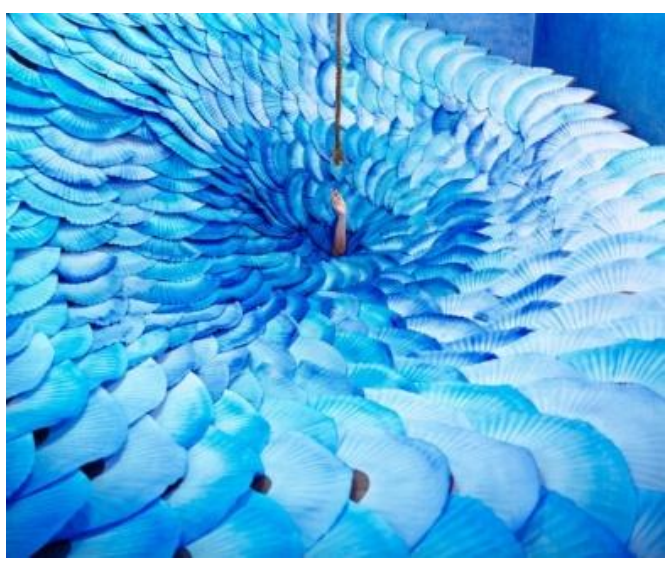

Figure 7: I will be backed (www.opiomgallery.com) [5]

Many of the topics that are rebuilt in Jee Yong's work are related to personal issues and private life of the artist. she tries to show her own psychological mood, and social status, including memories, successes, failures, happiness, and discomfort. Jee combines her personal experiences with what she has in mind. One of her works called Panic Room refers to her conflicts with her friends (Figure 8)

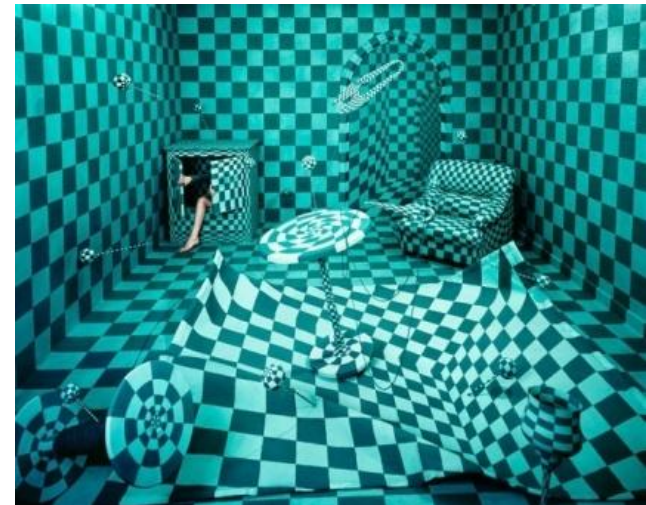

Figure 8: panic room (www.hungertv.com/feature/interview-jee-Yonglee) [4]

This ultimately leads to a change in the place of her life. Among the patterns of the Panic room, objects are flying in all directions, causing endless dizziness ."Treasure Hunt" is also another work of Jee based on the childhood memories of the artist. For this, Lee devoted three months of her time collecting thin, long leaves so that she could create a fantastic land (Figure 8).

Another point in the works of these two artists is the purpose of designing, construction, performance and presentation of the works. Skoglund is more of an installation artistic and the layout is part of the presentation of her work. The staging of her work is supported by museums and artistic foundations, with the aim of presenting them in museums and exhibitions and galleries. With a little change, they are used again and again. But Jee Yong Lee is just a photographer and arranges her staging for photography, not for live performance. Typically, works made for photography, depending on the photographer's point of view, can be in good or bad condition. On the other hand, works designed to be displayed and run in museums and galleries, due to the freedom of the audience to observe all angles and aspects of the work, are structured with more precision. Skoglund's works belong to the second group. Prior to taking photos, Skoglund does not even think of the photos she is going to take. She just concentrates on making the sculptures. She buys the raw materials and works for a long time to get to her design [11]. This is very different in the case of jeeYong. After designing the main structure and material preparation, she first defines the angle of her camera and then begins to construct and embed the elements in the final stage $[4,12,13]$.

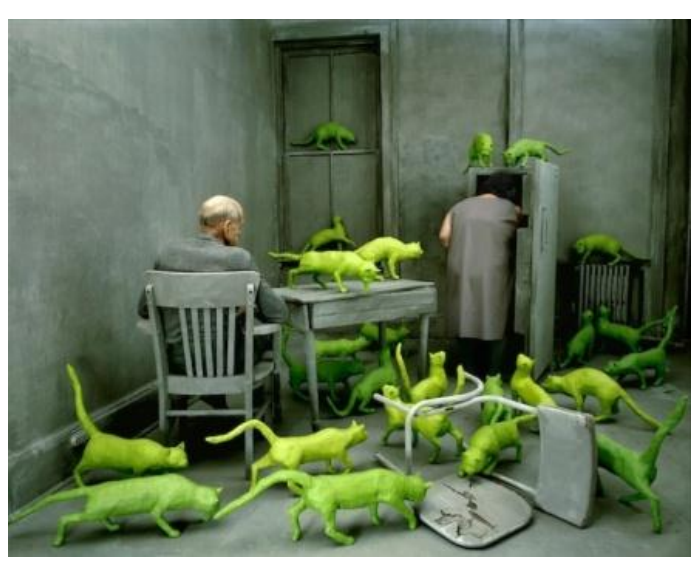

Figure 9: Radioactive Cats

Another aspect of the distinction between the works of these two artists is the use of color and appearance of the photos. Skoglund acts more economically in the use of color for stage elements, often incorporating elements in two or three colors alone, like Radioactive cats (Figure 9), and even sometimes just uses one color, but Jee Yong uses more diverse colors.

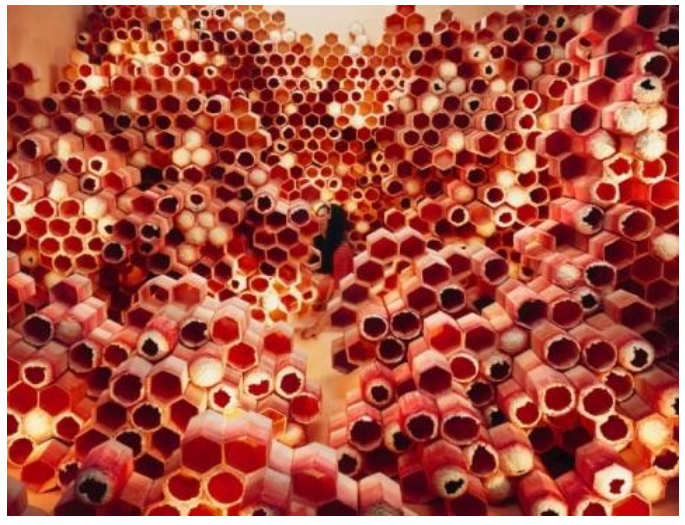

Figure 10: Flu (www.hungertv.com/gallery) [4]

Although in some works such as "the Flu" (Figure 10), Jee uses just two colors, and in some others such as "This is not enough" (Figure 11), she uses different tonalities of a single color, in majority of he works, various color schemes have been used.

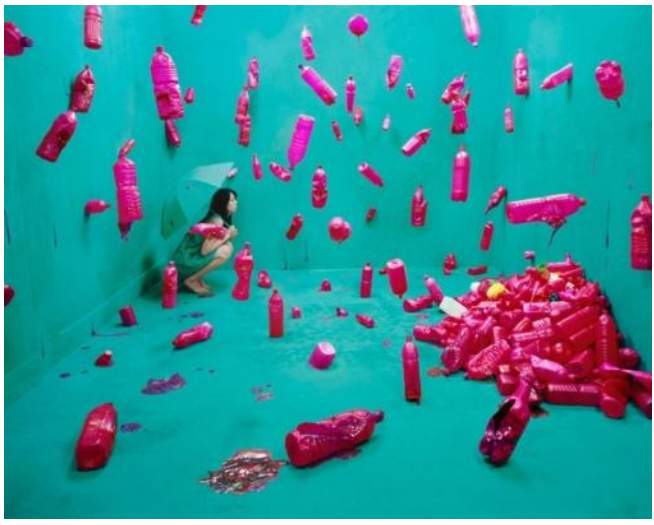

Figure 11: This is not enough (www.opiomgallery.com) [5]

\section{CONCLUSION}

Further investigations reveal many similarities and differences between the works of these two artists. Based on these findings, one can well judge the works of Jee Yong Lee. In principle, similarities indicate the impact while differences indicate creativity of the artists. The similarities seen between the two artists prove both artists are experts in the field of stage photography with Scaglund as pioneer, and Jee Yong as follower. However, the differences between the works of them represent the twisting of the path that the two are taking. The unbearable birth of artistic masterpieces is the result of Jee Yong's choice of a path different from Skagland. These differences, which are visible, both in terms of semantic load and in terms of visualization and compositional skills, although small, remove the name 
of Jee Yong from the list of copyrighted artists, and add to the value of her works.

The use of self-portrait is a superior feature of Yang Lee's work, which has been able to transfer the artist's feelings better than Skoglund. In addition, the emotional and literary themes contained in Lee's work have given an introverted aspect to Lee's works while the use of political and cultural aspects give an extroverted aspect to Scotland's pictures. As a result, Yang Lee's images are more popular among people while Sk0glund's works are popular with critics and art experts .The use of repetition, rhythm, color contrast, attractive sculptures, rotating order, etc. in Lee's work is inspired by Skoglund. However, the presence of the artist herself, the use of memories of personal life, and the use of tangible subjects and elements are among the innovations Lee has had. These innovations have made her works different from those of Skoglund, making her find lots of fans even among the fans of Skoglund.

\section{SUBSCRIPTS}

1- Pictorealism: An Art Photography movement in the mid-nineteenth century in Europe and the United States that developed the aesthetic nature of photography

2- John szarkowski: author, photographer and art critic - director of photojournalism at the Museum of Modern Art in New York - author of the book Looking at Photos

3- Victorian art: the art originated in England - a very good and effective presentation of various materials, various decorations

4- Photomontage: Combining elements in different photos and producing image with a new meaning and concept.

5- Andreas Vinkel

6- Tom hunter: An English photographer who often works on the reconstruction of classical paintings by photography and its techniques.

7- Sandy Skoglund

8- David levinthal: An American photographer who photographs small sculptures in his works.

9- Jan Groover: American female photography artist - Much of her photos are of kitchen tools.

10- Cindy Sherman: One of the most prominent post-modern photographers in the United States who pursues two arts ofphotography and performance simultaneously.

11- JeeYong Lee

12- Hongik University in Seoul

13- Opiomgallery

14- Reddit

15- Sovereign Art Prize

16- Shim Cheong

17- Ophelia: She is Hamlet's mistress in one of Shakespeare's famous stories, drowning herself in the water of the river.

18- The Minimalist Art School, which bases its works and expressions on the basis of simplicity and unadulterated methods.
19- Conceptual Art in which the expression of a particular concept, the most important aspect of its work and its purpose is only the presentation of thought, outside of any form and structure

20- George Pompidou

21- Leonardo da vinci

22- Leo Castelli Gallery

23- Salvador dali: was a supermanist painter and skilled designer who came to fame thanks to the creation of fantasy and surreal imagery.

24- Rene Magritte: was a Belgian surrealist painter

25- Man ray: with the original name of Emanuel Radinsky is an American photographer and an important developer of the Dada and Surrealist movement in photography.

26- Op art: The artistic movement that was derived from popular art in the sixties. The artists create a series of lines, shapes, and brightly colored levels of symmetry and concentration that appear vibrant, forward, and retrograde.

27- Installation: The Art School, which uses 3D sculptures and other media to convey a specific concept.

\section{REFERENCES}

[1] Khalaji, A., Arash. 2007. Fox Games (Introducing and Concert by Sandra Louisa Scagland). Tandis, 96.

[2] Sharifzadeh, Reza, M., Khademi, Shirin. 2014. Exploring the narrative element in staged photography with a look at works of Geoff Wall and Sandy Skoglund. Layout, Third Year, 7.

[3] Spiritualists, Zervan. 2014. Criticism A reality or constructed stage, reflection on staged photography. Tandis, 275.

[4] www.hungertv.com/feature/interview-jee-Yong-lee

[5] www.opiomgallery.com/en/artistes/oeuvresphotographe/17/jeeYo ng-lee

[6] Touraj, H., Tavakoli, Shahriyar. 2013. The Culture of World's Photographers, The Profession of the Artist.

[7] Panaro, Luca. 2008. This interview took place in connection with an exhibition at the Betta Frigieri Arte Contemporanea. Modena, Italy.

[8] Goldwater, Marge. 1988. Cross-References: Sculpture into Photography. Exhibition catalogue. Museum of Contemporary Art, Chicago, Illinois.

[9] www.mymodernmet.com/profiles/blogs/lee-jeeYong-stage-of-mindroom

[10] Heiferman, Marvin. 2001 .Serious Thoughts are Popping Up. In Sandy Skoglund: RainingPopcorn. Grinnell, Iowa: Faulconer Gallery, Grinnell College.

[11] Dreishpoon, Douglas. 2001. An Interview with Sandy Skoglund. In Sandy Skoglund: Raining Popcorn, Grinnell, Iowa: Faulconer Gallery, Grinnell College.

[12] www.dailymail.co.uk/femail/article-2520683/Artist-recreatesKorean-folk-tales-dreams-stories-incredible-art-tiny-room.html

[13] www.thisiscolossal.com/12/2013/jeeyong-lee-dreamscapes

[14] http://www.sandyskoglund.com/ 